\title{
Practical Management: \\ Impotence
}

Raymond E. Goodman, Medical Psychosexual Therapist, 41 Gibwood Road, Northenden, Manchester

At the initial interview the doctor should assess just what the patient means by 'impotence'. If present, its speed of onset, its duration and whether or not the patient has libido are important factors to consider. Do morning erections occur? Is ejaculation normal? It may be retrograde, premature or retarded. The presence of chronic disease, e.g. rheumatoid arthritis, hypertension, diabetes or depressive illness, may adversely affect potency, as may the drugs used in the treatment of these conditions.

Psychological methods involve the re-educating of the patient to correct any erroneous beliefs or unrealistic expectations that he may harbour. Behaviour therapies, e.g. the sensate focus procedures, require a sympathetic and motivated partner and an appropriate environment for their proper execution. In reality this is not always possible.

Many men will be helped by the above approaches. Others will need a physical assessment. This involves an overall examination reviewing all systems with special attention given to the autonomic nervous system and genital reflexes. Laboratory tests may be helpful to assess the hypothalamic/pituitary/gonadal system, and should include serum luteinising hormone, follicle stimulating hormone and prolactin, the latter is helpful to exclude the possibility of a pituitary tumour. Serum testosterone, bound and free if possible, should be measured. Appropriate further investigation of any pathology discovered may need to be undertaken. Nocturnal penile plethysmography is essential to help differentiate between psychological and organic impotence. The administration of testosterone and/ or other stimulant drugs may, if considered appropriate, be considered at this time.

Sex aids in the form of creams, penile rings, supports, pump mechanisms and vibrators have some value for certain men. ${ }^{1}$ Permanent penile implants are available today at centres mainly in the USA. Two basic types with similar degrees of acceptability are in use, namely the 'small carrion' and the 'inflatable'. In essence, the former consists of a silicon rod, one of which is implanted into each corporus cavernosus. This gives a permanently stiff penis, which can be kept pressed against the abdominal wall when not in use. The inflatable type consists of a fluid-filled system, with a pump placed in one scrotum joined to a reservoir fixed into the abdominal wall. By pressing the scrotum the patient can obtain an erection, and this can be made flaccid by his pressing a releasing valve. (For discussion see Melman ${ }^{2}$ and Small $^{3}$.)

The main indication for surgical implants seems to be for patients with organic impotence, especially those who have undergone major surgery for cancer, e.g. after abdominoperineal resection or cystectomy, where irreversible nerve damage has occurred, or patients with spinal cord injuries and pelvic fractures. Assessments of pre and post operative patients have shown that $90 \%$ of patients would elect to have surgery again in the same circumstances, even though many complained of a diminution of penis size, and a loss of sexual sensations, including feelings around ejaculation. A discussion of such factors, with both the patient and his wife, is very necessary for them to understand just what is involved and to give them realistic expectations for the future (for discussion see Segraves, Schoenberg \& Zarins", and Steege, Stout \& Carson ${ }^{5}$ ).

Drugs which facilitate erection by relaxing the cavernosal smooth muscles when given directly into the penis, such as papaverine and vasointestinal peptide are now available ${ }^{6}$. This approach should be considered before more drastic implant surgery is undertaken. Other procedures, i.e. epigastrocavernous anastomosis, for patients with arterial occlusion, have some adherents?

\section{REFERENCES}

${ }^{1}$ HasL.AM, M. T. (1976) Sexual aids. Update, 12, 883-886.

${ }^{2}$ MeLMAN, A. (1978) Development of contemporary surgical management for erectile impotence. Ibid, 1, 272-281.

${ }^{3}$ SmalL, M. P. (1978) The Small-Carrion penile prosthesis: surgical implant for the management of impotence. Ibid, 1, 282-291.

${ }^{4}$ Segraves, R. T., Schoenberg, H. W. \& Zarins, C. K. (1982) Psychosexual adjustment after penile prosthesis surgery. Ibid, $\mathbf{5}$, 222-229.

${ }^{5}$ Steege, J. F., Stout, A. L. \& Carson, C. C. (1986) Patient satisfaction in Scott and Small-Carrion penile implant recipients: a study of 52 patients. Archives of Sexual Behavior, 15, 393-399.

${ }^{6}$ BrINDLEY, G. S. (1986) Maintenance treatment of erectile impotence by cavernosal unstriated muscle relaxant injection. British Journal of Psychiatry, 149, 210-215.

'Michael, V., Kramar, R., Posphical, J. \& Hejhal, L. (1976) Arterial epigastricocavernous anastomosis for the treatment of sexual impotence. World Journal Surgery, 1, 515-520.

\section{John Money Archive}

Dr June Machover Reinisch, Director of The Kinsey Institute for Research in Sex, Gender, and Reproduction, has announced that the Institute has received a major collection of research materials, personal papers and works of art from Dr John Money, a pioneer in the investigation of issues relating to sexuality and gender.
Researchers who would like to work with the materials in this archive are asked to apply to: June Machover Reinisch, $\mathrm{PhD}$, Director, The Kinsey Institute for Research in Sex, Gender, and Reproduction, Morrison Hall, Indiana University, Bloomington, IN 47405, USA. 